\title{
Effect of Surface Finish Reflectance on Energy Consumed by Lighting
}

\author{
Ammar ALKHALIDI ${ }^{1 *}$, Shahd SHAMMOUT ${ }^{2}$, Mohamad K. KHAWAJA ${ }^{3}$ \\ ${ }^{1}$ University of Sharjah, Sustainable and Renewable Energy Department, Sharjah, UAE \\ ${ }^{1-3}$ German Jordanian University, Energy Engineering Department, Amman, Jordan
}

\begin{abstract}
Efforts from both spatial and energy engineers were conceived in order to reduce the total running costs of electric consumption in buildings. An often-overlooked energy and money saving opportunity for the built environment lies in lighting. This study investigates the effect of room interior finish on electrical lighting energy consumption. Walls, ceiling, and floor finish, in accordance to light reflectance values, were taken at low reflectance model (LRM), medium reflectance model (MRM), and high reflectance model (HRM). Various occupied spaces were classified in accordance to physical dimensions and capacity in order to cover a wide range of space usage and standard illuminance requirements. It was found that the HRM reduced power consumption in lighting by about $40.62 \%$ compared to the LRM in the case for medium museum halls, with energy saved rating at about $2.32 \mathrm{GWh}$ annually; other occupied spaces show a saving potential between $22.00 \%$ and $40.00 \%$.
\end{abstract}

Keywords - Built environment; energy consumption; light reflectance value; lighting design

\section{INTRODUCTION}

While the built environment is a foundational component of civilization, it is still the largest source of pollution cumulatively [1] Energy efficiency, the consumption of a lesser amount of energy to receive the same output in a process, plays a role in alleviating pollution [2]. Proper design, in which energy efficient measures are considered, helps reduce the amount of harmful contaminants that would otherwise be sent into the atmosphere [3].

In buildings, energy efficient practices of lighting improvement significantly reduce electrical energy consumption, yet they are often forgotten [4]. Lighting is considered one of the main energy-consuming activities in all types of buildings. Lighting is the second largest energy consumer in commercial buildings in the United States with $17 \%$ of total energy use in 2012 [5]. A 2018 study based on Al-Ahliyya Amman University in Jordan found that lighting made up $4 \%$ of the total electric power consumption on campus [6].

A plethora of efforts throughout the years have been spent by professionals to reduce the energy consumed by lighting [7]-[9]. The effect of surface finish reflexivity of the walls, ceiling, and floor of various case-study occupied spaces on electrical energy consumed in lighting is discussed in this study.

Energy saving, first and foremost, translates to money saving. In Germany, the average enduser electricity tariff is 0.37 USD per $\mathrm{kWh}$ consumed [10]. In the United Kingdom, $1 \mathrm{kWh}$ costs an average of 0.27 USD [10], while in Jordan, the average cost of $1 \mathrm{kWh}$ is up to 0.35

\footnotetext{
* Corresponding author.

E-mail address: ammar.alkhalidi@gju.edu.jo
} 
USD [11]. Additionally, the more energy is saved, the less harmful emissions are produced from coal, gas, and oil-fired powerplants. In other words, the importance of energy-saving activities, and thus, energy management lies mainly in its economic and environmental value. For each $\mathrm{kWh}$ of electricity saved globally, $0.480 \mathrm{~kg}$ of carbon dioxide emissions is reduced [12].

When studying lighting, the three main parameters are i) lighting types, ii) illumination level required in accordance to the application, and iii) surface reflectance of materials used interiorly in accordance to colour and material type.

In terms of lighting energy efficiency, it is important to note the efficacy of the light bulb, or its desired output of luminous flux in lumens to its input power in Watts [13]. Other important parameters are luminance; a measure used to indicate the brightness of a source in candelas per square meter, and illuminance; a measure used to indicate the light falling on a surface in lux [14]. Table 1 shows the required levels of illuminance needed in different real-life applications.

TABLE 1. ILluminANCE LEVELS FOR DifFERENT REAL-LIFE APPLICATIONS [13], [15], [16]

\begin{tabular}{lcc}
\hline Application & Minimum Illuminance, lux & Maximum Illuminance, lux \\
\hline Retail & 400 & 500 \\
Office & 500 & 500 \\
Video terminal work & 100 & 200 \\
Classroom & 300 & 500 \\
Hospital public areas & 100 & 200 \\
Hospital operating theatre & 1500 & 2000 \\
Places of worship & 150 & 500 \\
Museums & 50 & 200 \\
Electronic test room & 800 & 1200 \\
Factory assembly areas & 200 & 500 \\
\hline
\end{tabular}

The European Committee for Standardization (CEN) published the EN 12464-1 Standard in November 2002 for the requirement of lighting conditions for different tasks and work places [17]. As of 2003, the Standard has been mandatory to implement in the European Union.

The CEN also published the EN 15193-1, which details the energy requirements for lighting under the energy performance of buildings. The EN 15193-1 standard discusses the proper procedures in order to estimate energy requirements of lighting in buildings and to give a methodology for a numeric indicator of energy performance of buildings [18].

For a lecture hall, lighting should provide 500 lux of illuminance [13]. Wall illuminance should be 80 lux, and ceiling illuminance should be 50 lux, with a colour rendition of 0.8 and 19 glare rating [18].

For the interiors of any space in a building, the reflectance of the surfaces inside the room should be considered, namely for the floor and walls. Light reflectance value is defined as the total amount of useful light reflected by a surface in all directions at all wavelengths when beamed by a light source [19]. A reflection coefficient or a reflection factor ( $\rho v)$ is the ratio of total amount of light reflected in comparison to the amount of light shed on the surface.

The reflection factor of any surface depends mainly on the surface material and its colour. For example, painted gypsum plastering has a light reflectance value of 0.85 , whereas linoleum wood has a light reflectance value of 0.25 [8]. Moreover, white floor tiles tend to 
have a higher light reflectance value of $70.90 \%$ than for black tiles [20]. Reflectance coefficients range $0.60-0.90$ for ceilings, $0.30-0.80$ for walls, and $0.10-0.50$ for the floor, are recommended for the major interior surfaces [17].

DIALux evo 6.1 was used for simulating different surfaces with different light reflectance values proved that the luminance of a certain area increased from 133.00 lux to 213.00 lux as the light reflectance value increased, all while keeping the lighting system and room dimensions constant and within the range of recommended light reflectance value values by CEN [8].

DIALux evo and Luminous are most widely used simulation tools for lighting design. While Luminous is more concerned with space design, and thus more useful for architects, DIALux evo provides extensive data regarding surface characteristics, and power and energy use of a variety of light bulbs.

An analysis of the relationship between the reflectance of interior surfaces and the distribution of artificial light was achieved through the SPSS statistical assessment of visual comfort indices of DIALux evo 6.1 simulations; although mentioned, the energy saving potential of the findings of the study was not defined [8].

An investigation into the effects of different design strategies on lighting energy use and visual comfort level, using DIALux evo 7.00 to simulate the models studied. It proved that surfaces of the highest reflectance provide the best energy use and visual comfort; while an energy saving potential of $45.00 \%$ was achieved by switching from low reflectance surfaces to high reflectance ones, the model in question was specific to a work office [7].

Up to the authors' knowledge, the relationship between surface finish reflectance and the electric energy consumed in lighting has not been clearly reported. Therefore, it was decided to address that relationship in a range of occupied spaces.

\section{METHODOLOGY}

\subsection{Space Classification}

Four types of occupied space with varying purposes were chosen for this study, in order to determine the feasibility of the research concept over a wide range of usage, area, and occupancy. Spaces were classified according to physical room dimensions into large, medium, and small rooms as listed in Table 2.

TABLE 2. ClassificAtion OF THE OCCUPIED SPACES ACCORDING TO DIMENSIONS AND CAPACITY [21]-[25]

\begin{tabular}{|c|c|c|c|c|}
\hline Occupied space & Offices & Classrooms & Places of worship & Museums \\
\hline \multicolumn{5}{|l|}{ Dimensions } \\
\hline Large area & $16 \times 14 \times 3 \mathrm{~m}$ & $9 \times 7.20 \times 3 \mathrm{~m}$ & $50 \times 25 \times 9 \mathrm{~m}$ & $24 \times 24 \times 4.16 \mathrm{~m}$ \\
\hline Medium area & $4.80 \times 3.60 \times 3 \mathrm{~m}$ & $7 \times 5.50 \times 3 \mathrm{~m}$ & $26 \times 24 \times 10 \mathrm{~m}$ & $5.25 \times 38.70 \times 6.40 \mathrm{~m}$ \\
\hline Small area & $3.40 \times 2.90 \times 3 \mathrm{~m}$ & $5.60 \times 4.50 \times 3 \mathrm{~m}$ & $21 \times 19 \times 9 \mathrm{~m}$ & $10 \times 10 \times 3.50 \mathrm{~m}$ \\
\hline \multicolumn{5}{|c|}{$\begin{array}{l}\text { Occupant capacity (The occupant capacity of office and museum occupied spaces could not be determined due to th } \\
\text { differing nature and context for such spaces, thus approximated for offices and left blank for museums) }\end{array}$} \\
\hline Large area & 5-75 persons & 32 persons & 1345 persons & - \\
\hline Medium area & $\begin{array}{l}1 \text { executive with } \\
1 \text { meeting table }\end{array}$ & 25 persons & 650 persons & - \\
\hline Small area & 1 person & 20 persons & 415 persons & - \\
\hline
\end{tabular}


To impose a classification method based on the space use alone would not be enough without considering the difference sizes an occupied space could exist in. Thus, the classification method for occupied spaces in this study was based on both the size and space use to particulate both elements consequently. Occupant capacity is also approximated as to offer a different indicator on the size of the occupied space.

The example on the large museum hall-type space studied is Special Gallery 2 in the Islamic Art Museum of Malaysia [25], while the medium-sized museum hall could be found in museums such as SHOTO Museum in Japan [24]. The small museum hall is conventional for small, local museums [23].

\subsection{Computer Simulation Validation}

To prove the validity of the computer simulation, a 1:10 model of a real-life lecture hall was built as shown in Fig. 1(a). The model had dimensions of $1 \times 0.50 \times 0.30 \mathrm{~m}$, with a work surface at $0.08 \mathrm{~m}$, and was then simulated using DIALux evo 8.2 as shown in Fig. 1(b). Data was collected using an IR thermometer with $\pm 0.01 \%$ tolerance and a TENMARS (TM-208) light intensity meter, with $\pm 0.01 \%$ tolerance. An LED light strip of $8 \mathrm{~W}$ rated power, 366 lumens of luminous flux, 1 meter of length and 122 chips per meter was used in both the physical and simulated models. Three reflectance profiles were used in both modelling tools as in Table 3. Fig. 2 shows the lighting scheme for the classroom type occupied space.

Reflectance models were created in accordance to CEN standards. It was important not to exceed the glare allowed by disregarding standards for user comfort reasons. The physical model was built using blue expanded polystyrene (EPS) insulation boards as the ones used in building construction and was painted with emulsion paint, in an effort to simulate the actual room and to avoid mixing material with different reflectance coefficients.

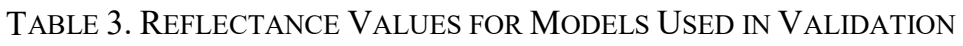

\begin{tabular}{llll}
\hline \multicolumn{4}{c}{ Reflectance coefficient model } \\
\hline & LRM & MRM & HRM \\
Ceiling & 0.60 & 0.70 & 0.88 \\
Floor & 0.15 & 0.30 & 0.50 \\
Walls & 0.30 & 0.60 & 0.70 \\
\hline
\end{tabular}

The thermal conductivity $(\lambda)$ of the insulation board is $0.04 \mathrm{Wm}^{-1} \mathrm{~K}^{-1}[26]$ and a thickness of $3 \pm 0.03 \mathrm{~cm}$. The thermal transmittance ( $U$-Value) $\mathrm{Wm}^{-2} \mathrm{~K}^{-1}$ was calculated following Eq. (1):

$$
U=\frac{\lambda}{d}
$$

where

$U \quad$ Value thermal transmittance of the wall;

$\lambda \quad$ Thermal conductivity of the material;

$d \quad$ Thickness of the wall.

A $U$-Value of $1.3 \mathrm{Wm}^{-2} \mathrm{~K}^{-1}$ was obtained, indicating proper insulation properties of EPS boards. However, since an LED light strip was used in the model, no remarkable increase in temperature inside the model was noticed, thus proving that the reflectance models had no effect on the thermal comfort within the space. Measurements were taken at 16 points over 
the area of the model and at a $0.08 \mathrm{~m}$ height in order to provide accurate data. The average illuminance was then calculated and compared.
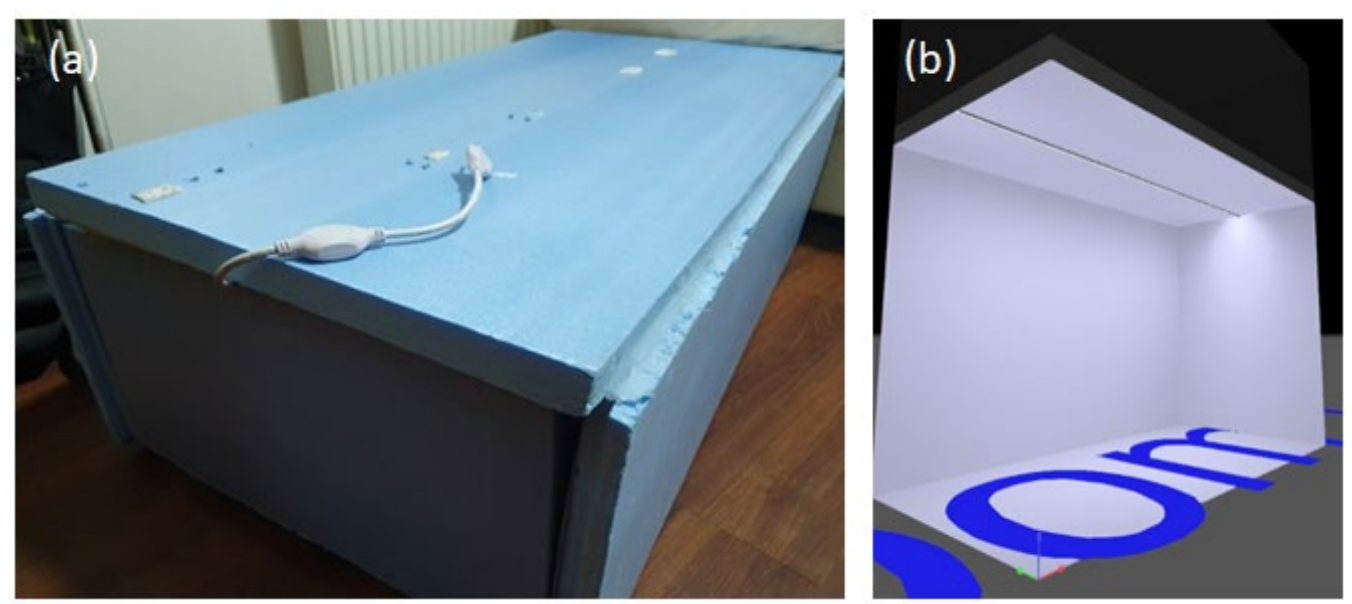

Fig. 1. a) Physical model; b) simulated model.

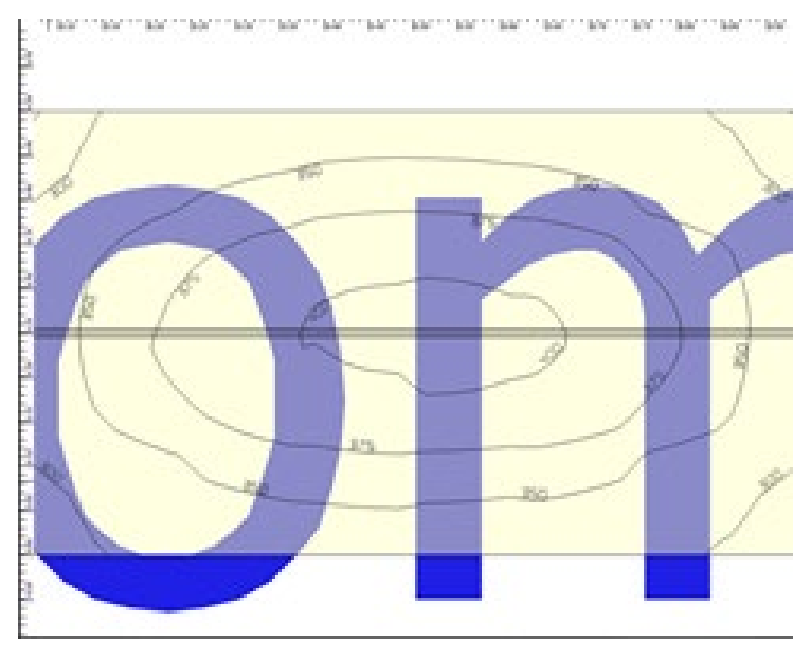

Fig. 2. Lighting scheme for classroom type occupied space.

The results were obtained at an approximately 300 lux level, the minimum recommended illuminance level by CEN. To do so at different reflectance models, LED chips were taped off securely and their power was neglected. Table 4 shows the results obtained through the physical model against those obtained via computer simulation.

The average error from the three different models was recorded at $0.93 \%$ between both the simulated and modelled values. Moreover, three consecutive tests were conducted on the HRM, with a resulting standard deviation of 0.76 lux, which is considered marginally small when studying lighting [7]. The results confirmed that the computer simulation was valid. 
Table 4. Results Obtained from Physical Model vs. Simulated Model

\begin{tabular}{lllllll}
\hline & \multicolumn{5}{l}{ Physical model } & \multicolumn{4}{l}{ Simulated model } \\
\hline Model & LRM & MRM & HRM & LRM & MRM & HRM \\
Illuminance, lx & 261.00 & 301.00 & 304.00 & 264.00 & 300.00 & 308.00 \\
Luminous flux, lm & 366.00 & 308.00 & 244.00 & 366.00 & 308.00 & 244.00 \\
Power, W & 8.00 & 6.80 & 5.40 & 8.00 & 6.80 & 5.40 \\
\hline
\end{tabular}

For the purposes of validating the economic value found in the study independent of geographical location, three examples countries representing three varying price points of electrical energy end-user tariffs were investigated: high cost, as found in Germany, medium cost, as the case of Jordan, and low cost, with the United Kingdom taken as an example.

TABle 5. Standard DeViation Between the Physical and Simulated Modelling of the LiGHT REFLECTANCE MODELS

\begin{tabular}{llll}
\hline & \multicolumn{3}{c}{ Light coefficient model } \\
\hline & LRM & MRM & HRM \\
Illuminance standard deviation, lx & 1.50 & 0.50 & 2.00 \\
\hline
\end{tabular}

The simulations were run at illuminance levels such as in Table 1 whilst neglecting daylight illumination. All rooms were considered clean with scheduled maintenance, so the light loss factor was at 0.80 .

\section{RESUlts}

The electric energy consumption in lighting for the classified occupied spaces in Table 2 over the three different light reflectance models is shown in Fig. 3. Fig. 4 shows the money saving potential which lies in switching from LRM to HRM in three test countries in USD. A detailed analysis of each occupied space can be found in the following subsections.

\subsection{Office-Type Occupied Spaces}

Up to $33.33 \%$ reduction in electric consumption could be reached if the colours of the lowreflectance internal surfaces were replaced with ones of higher reflectance coefficients in case of small offices. Furthermore, a great saving potential lies in replacing LRM with HRM and has been found to reach $25 \%$ in medium-sized offices and $27.5 \%$ in large offices, where $1875.50 \mathrm{kWh}$ could be saved, amounting to more than $900.00 \mathrm{~kg}$ of carbon dioxide emissions annually.

Savings in medium and small-sized offices was found to be equal. However, the money saving potential in small-sized offices per unit area is larger than that of medium-sized offices. While $22.83 \mathrm{USD} / \mathrm{m}^{2}$ was saved on average in the small office, $13.02 \mathrm{USD} / \mathrm{m}^{2}$ was spared in medium offices. 


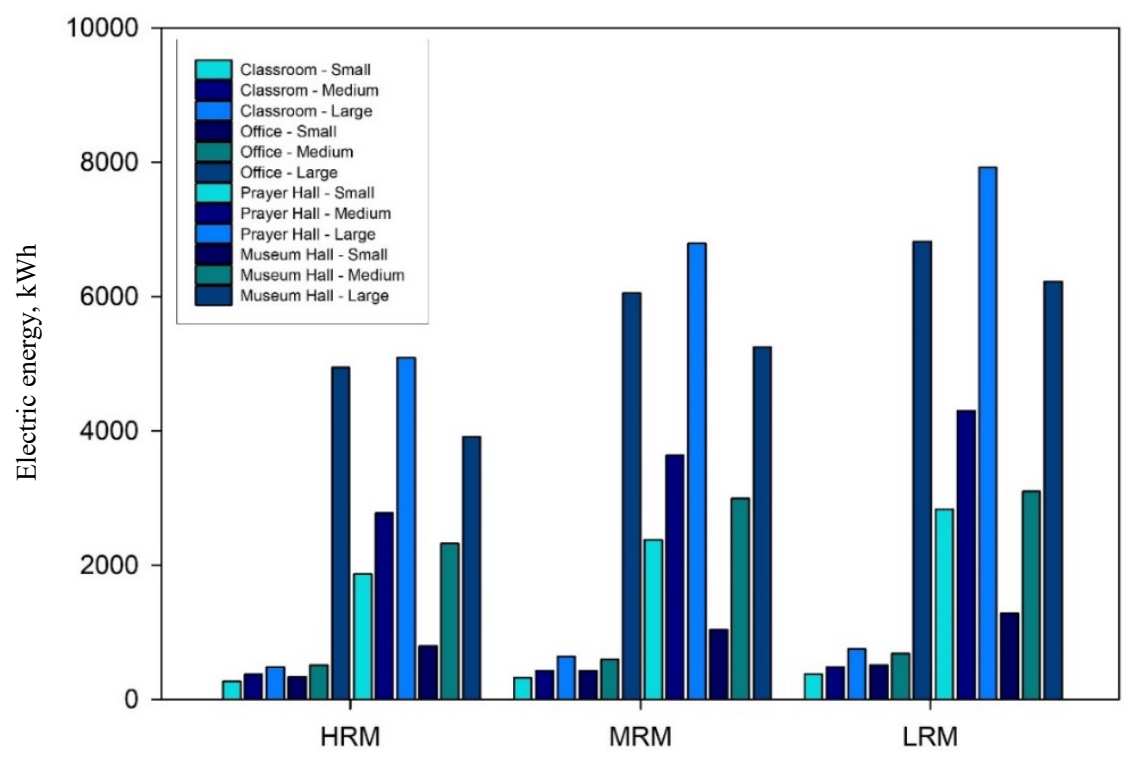

Light reflectance model

Fig. 3. Electric energy consumed by lighting [kWh] in classified occupied spaces for simulated High Reflectance Model, Medium Reflectance Model, Low Reflectance Model.

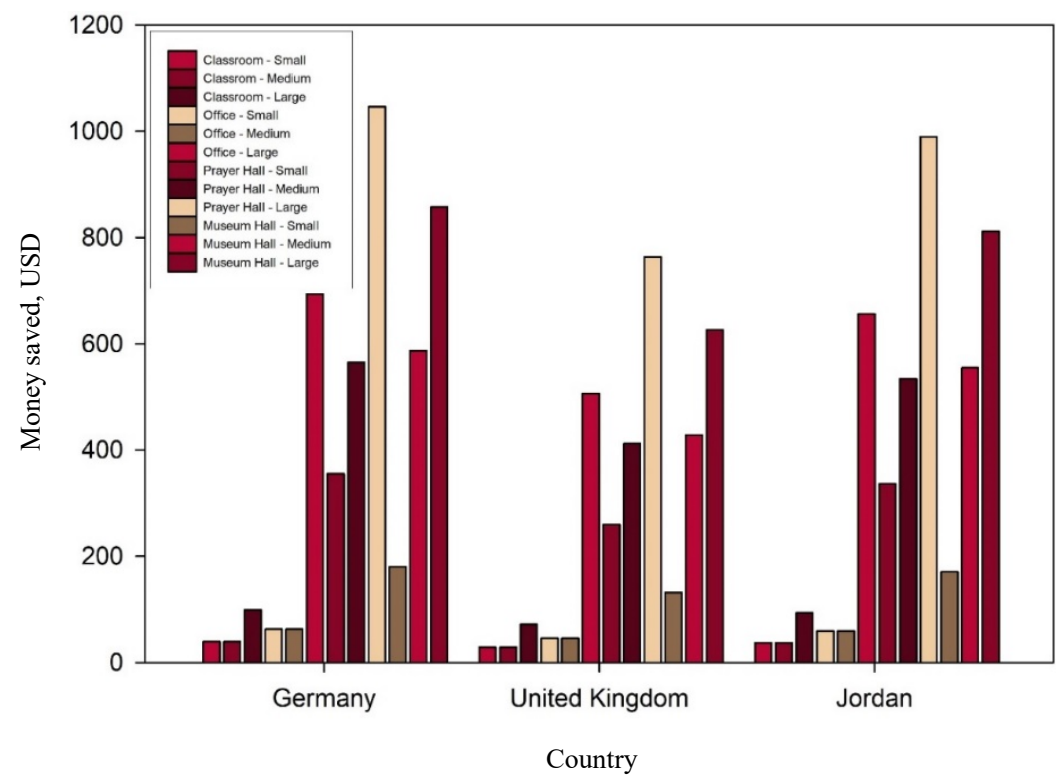

Fig. 4. Money saving potential [USD] by switching from Low Reflectance Model to High Reflectance Model in classified occupied spaces in three test countries. 


\subsection{Classroom-Type Occupied Spaces}

Large classrooms offer a bigger power-saving opportunity at $35.71 \%$ compared to mediumsized classrooms at $22.22 \%$ and small-sized classrooms at $28.57 \%$. The power saving opportunity was obtained by switching LRM with HRM. In addition to that, electric energy consumed by lighting dropped drastically when HRM was applied to large, medium, and small-sized classrooms.

Savings by applying HRM instead of LRM in classrooms was the highest in Germany for the large classroom, at USD 99.00 per annum as presented in Fig. 4. For medium and smallsized classrooms, the amount of money saved was identical, with the small-sized classroom outperforming in terms of money saved per unit area.

\subsection{Places of Worship}

Both money and energy saving potentials in the prayer hall, for all three size classifications were significant mainly due to the high ceilings and large occupied area in those spaces. The energy saving opportunity increased with increased area. An average of $35.1 \%$ of power consumed in lighting was saved for all size categories. Moreover, a staggering annual energy saving opportunity of $2264.00 \mathrm{kWh} / \mathrm{m}^{2}$ was found by applying HRM in place of LRM in the large prayer hall, resulting in carbon dioxide emissions reduction by $1357.80 \mathrm{~kg}$.

In terms of running cost reduction, USD 1046.64 could be saved annually by applying HRM instead of LRM in a large prayer hall in Germany. For the same prayer hall, USD 763.76 would be saved by applying HRM in the United Kingdom, and USD 990.10 in Jordan. Furthermore, USD 565.18 could be saved by applying HRM instead of LRM on a mediumsized prayer hall in Germany.

\subsection{Museum Hall-Type Occupied Spaces}

A tremendous saving potential in both power and energy of an average of $39.3 \%$ is found in museum hall-type spaces. In the large museum hall, $4027.78 \mathrm{kWh} / \mathrm{m}^{2}$ could be saved annually by applying HRM instead of LRM, amounting to 1.11 tons of carbon dioxide emissions yearly. The amount of energy reduction translates to USD 858.10 saved in Germany for the large museum hall case study.

\section{Conclusions}

Lighting is a large electric energy consumer in all types of buildings. In this study, the effect of the light reflectance of interior finish on electrical energy consumed by lighting in various occupied spaces was investigated. Occupied spaces were classified in accordance to area into three categories: large, medium, and small. Whereas four general types of occupied space were studied in order to cover a wide variety of usage and standard illuminance requirements: offices, classrooms, prayer halls, and museum halls.

Three colour models based on colour reflection factors were built: low reflectance model (LRM), medium reflectance model (MRM), and high reflectance model (HRM). A computer simulation was found to be valid when compared to the physical experimental results with a $\pm 1 \%$ recorded variation.

It was concluded that a remarkable energy saving opportunity, and therefore, a money saving potential lies in the adaptation of HRM in all occupied spaces investigated. An average $39.1 \%$ of total lighting energy consumption is reduced when replacing LRM with HRM in museum hall-type spaces. 
It was found that all occupied spaces over the spectrum of size classification recorded a saving potential in energy varying between $22 \%$ and $40 \%$, deeming the results of the model highly efficient and acceptable for all spaces.

The investigated method of using surface reflectance in power consumption reduction is also useful to avoid harmful emissions by reducing the use of electricity generated by coal, gas, and oil-fired powerplants. Future research opportunities lie in implementing HRM in medical care centres, laboratories, as well as research centres.

\section{REFERENCES}

[1] Alkhalidi A., Zaytoun Y. N. Reuse Waste Material and Carbon Dioxide Emissions to Save Energy and Approach Sustainable Lightweight Portable Shelters. Environmental and Climate Technologies 2020:24:143-161. https://doi.org/10.2478/rtuect-2020-0009.

[2] Jaffe A. B., Stavins R. N. The energy-efficiency gap What does it mean? Energy Policy 1994:22(10):804-810. https://doi.org/10.1016/0301-4215(94)90138-4

[3] Alkhalidi A., et al. Is it a possibility to achieve energy plus prefabricated building worldwide? International Journal of Low-Carbon Technologies 2021:16:220-228. https://doi.org/10.1093/ijlct/ctaa056.

[4] Belany P., Hrabovsky P., Kolkova Z. Combination of lighting retrofit and life cycle cost analysis for energy efficiency improvement in buildings. Energy Reports 2021:7:2470-2483. https://doi.org/10.1016/j.egyr.2021.04.044

[5] US Energy Information Administration. Commercial Buildings Energy Consumption Survey 2012: Trends in Lighting in Commercial Buildings [Online]. [Accessed 24.10.2021]. Available: https://www.eia.gov/consumption/commercial/reports/2012/lighting

[6] Hassan W. H., Alkhalidi A. Comparing Between Best Energy Efficient Techniques Worldwide with Existing Solution Implemented in Al-Ahliyya Amman University. International Journal of Thermal and Environmental Engineering 2018:17:1-10. https://doi.org/10.5383/ijtee.17.01.001.

[7] Makaremi N., et al. Effects of surface reflectance and lighting design strategies on energy consumption and visual comfort. Indoor and Built Environment 2019:28:552-563. https://doi.org/10.1177/1420326X18793170.

[8] Makaremi N., et al. Quantifying the effects of interior surface reflectance on indoor lighting. Energy Procedia 2017:134:306-316. https://doi.org/10.1016/j.egypro.2017.09.531.

[9] Li X., et al. Design and analysis of an active daylight harvesting system for building. Renewable Energy 2019:139:670-678. https://doi.org/10.1016/j.renene.2019.02.097.

[10] Eurostat. Electricity price statistics - Statistics Explained, European Commission [Online]. [Accessed 24.10.2021]. Available: https://ec.europa.eu/eurostat/statistics-explained/index.php?title=Electricity_price_statistics

[11] National Electric Power Company (NEPCO). Home Page [Online]. [Accessed 24.10.2021]. Available: https://www.nepco.com.jo/en/Default_en.aspx

[12] Sadeque Z., et al. A knowledge note series for the energy practice scaling. Up Access to Electricity: The Case of Bangladesh. Washington: WBG, 2014.

[13] Ransen O. Candelas, Lumens and Lux. Illumination Engineering. 2013.

[14] Rash C. E., McGowin E. Measuring light, Information Display. 1996.

[15] Scuello M., et al. Museum Lighting: Optimizing the illuminant. Color Research and Application 2004:29(2):121127. https://doi.org/10.1002/col.10231.

[16] Holmes D. Lighting for the Built Environment: Places of Worship. 2016.

[17] EN 12464-1:2002. Light and Lighting, Light and lighting - Lighting of work places - Part 1: Indoor work.

[18] PrEN 15193: Energy performance of buildings - Energy requirements for lighting Contents. 2006:15193.

[19] Gooch J. W. Light Reflectance. In Gooch J.W. (eds) Encyclopedic Dictionary of Polymers. New York: Springer, 2011:426-426. https://doi.org/10.1007/978-1-4419-6247-8_6899.

[20] Kamalakannan C., et al. Power Electronics and Renewable Energy Systems. Proceedings of ICPERES 2014. 2014. https://doi.org/10.1007/978-81-322-2119-7.

[21] Neufert P., et al. Neufert Architect's Data, 4th ed. New Jersey: John Wiley \& Sons, 2009.

[22] Al-ajmi F. F., et al. Indoor Environmental Quality in Air-conditioned Mosque Buildings in Kuwait. American Journal of Civil Engineering and Architecture 2017:5:167-173.

[23] Kramer R. P., Schellen H. L., Van Schijndel J. W. M. Towards temperature limits for museums: A building simulation study for four museum zones with different quality of envelopes. Proceedings of the Healthy Buildings Europe Conference, 2015.

[24] The SHOTO Museum of Art. Overview of the Museum. [Online]. [Accessed: 27.10.2021]. Available: https://shotomuseum.jp/en/aboutthemuseum/outline/

[25] Dario Castellino. 2001. Exhibition Museum 4. [Online]. [Accessed: 27.10.2021]. Available: https://www.dariocastellino.it/en/project/exhibition-space-4/ 
[26] Yang L., Yang J., Liu Y., An Y., Chen J. Hot box method to investigate U-values for straw bale walls with various structures. Energy and Buildings 2021:234:110706. https://doi.org/10.1016/j.enbuild.2020.110706 